\title{
Sulfato de amônio e uréia em cobertura no milho em semeadura direta no Cerrado
}

\author{
Anderson Lange ${ }^{1}$, Waldo Alejandro Ruben Lara Cabezas² e Paulo César Ocheuze Trivelin ${ }^{3}$
}

\section{RESUMO}

A aplicação de nitrogênio no milho de forma antecipada, tanto na semeadura da planta de cobertura como em présemeadura pode otimizar os trabalhos dentro da propriedade. Objetivou-se avaliar a influência nas concentrações foliares e produtividade de grãos do milho do parcelamento do nitrogênio suplementar à semeadura em área de dois anos de soja, em solo de textura média e quantificar a recuperação do nitrogênio do sulfato de amônio e da úreia, utilizando a técnica da diluição isotópica $\left({ }^{15} \mathrm{~N}\right)$. Os tratamentos constaram da aplicação de $110 \mathrm{~kg}$ ha ${ }^{-1}$ de nitrogênio em épocas distintas: na semeadura do milheto - 5 dias antes da semeadura do milho - em cobertura, quando as plantas tinham 5-7 folhas; - e em cobertura quando as plantas tinham 9-10 folhas. Há diferença de produtividade de grãos e concentrações foliares de nitrogênio, fósforo, cálcio e enxofre quando se aplica nitrogênio suplementar à semeadura em diferentes épocas em relação a ausência de fertilização. O parcelamento de $110 \mathrm{~kg}$ ha $^{-1}$ entre pré-semeadura e cobertura ou apenas na cobertura não altera a recuperação total do fertilizante. A recuperação do nitrogênio do sulfato de amônio aplicado em cobertura é maior quando comparada à uréia, sendo ainda que o parcelamento de sulfato de amônio em cobertura apresenta maior recuperação em relação ao fornecimento em uma única aplicação.

Palavras-chave: Zea mays, pré-semeadura, N recuperado na planta, épocas de aplicação.

\section{ABSTRACT}

\section{Timing and sources of sidedress nitrogen on no-tillage corn two years after soy crop}

$\mathrm{N}$ application to corn both at planting and preplant can optimize farm work. The aim of this study was to evaluate the effect of split supplemental nitrogen applications on leaf $\mathrm{N}$ content and corn yield, two years after soybean crop, in a sandy clay loam soil and quantify $\mathrm{N}$ recovery using isotopic dilution $\left({ }^{15} \mathrm{~N}\right)$. The treatments consisted of $110 \mathrm{~kg}$ ha${ }^{1}$ nitrogen applied at different times: at planting; 5 days preplant; sidedress (5-7 leaves); and sidedress (9-10 leaves). Difference was found for corn yield and leaf content of $\mathrm{N}$, phosphorus, calcium and sulphur when supplemental nitrogen was applied after planting in different times compared with no supplemental application. Split application of $110 \mathrm{~kg} \mathrm{ha}^{-1} \mathrm{~N}$ between preplant and sidedress or sidedress only did not affect total $\mathrm{N}$ recovery. The recovery of nitrogen from sidedress ammonium sulfate was higher than from urea. Split of sidedress ammonium sulfate led to higher $\mathrm{N}$ recovery than a single application.

Key words: Nitrogen recovery, preplant, time of application, Zea mays.

Recebido para publicação em setembro de 2009 e aprovado em novembro de 2010

${ }^{1}$ Engenheiro Agrônomo, Doutor. Universidade Federal de Mato Grosso, Câmpus de Sinop. Rua Alexandre Ferronato, 1200. Distrito Industrial. CEP 78550-000; Sinop-MT; paranalange@hotmail. Engenheiro Agrônomo, Doutor. Agência Paulista de Tecnologia dos Agronegócios, Pólo Regional Nordeste Paulista, CEP 15500-970 Votuporanga, SP. waldolar@aptaregional.sp.gov.br.

${ }^{3}$ Engenheiro Agrônomo, Doutor. Centro de Energia Nuclear na Agricultura, Caixa Postal 96, CEP 13400-970 Piracicaba, SP. pcotrive@cena.usp.br 


\section{INTRODUÇÃO}

O sistema semeadura direta (SSD) trouxe dificuldades de manejo, sendo muitas já estudadas e discutidas na região Sul do país. Destaque é dado à necessidade da palha cobrir o solo e a correta época para a aplicação do nitrogênio na cultura do milho (Aita et al., 1994; Sá, 1999; Basso \& Ceretta, 2000; Borkert et al., 2003). Na região do Cerrado, devido às condições de clima diferenciadas na região Sul, muitas adaptações foram e estão sendo feitas para que a técnica possa ser usada com sucesso e assim contornar os problemas.

A antecipação da cobertura nitrogenada, destinada à cultura do milho, aplicada na semeadura da planta de cobertura ou em pré-semeadura no milho tem sido estudada e os resultados de produtividade de grãos podem apresentar similaridade com a aplicação em cobertura. Porém, em anos de elevada pluviosidade ficou constatado que a produtividade pode reduzir (Sá, 1999; Basso \& Ceretta, 2000; Pauletti \& Costa, 2000; Lara Cabezas et al., 2004; Pottker \& Wietholter, 2004; Lara Cabezas et al., 2005).

Na região Sul o objetivo da aplicação em pré-semeadura é a redução da competição entre a cultura do milho e o solo (imobilização) pelo $\mathrm{N}$ aplicado na semeadura. Na região do Cerrado, especificamente no Triângulo Mineiro, a antecipação da aplicação de $\mathrm{N}$ vem sendo utilizada com o objetivo de otimizar o cronograma operacional da fazenda, pois a maior parte das áreas é cultivada com soja. Nesta situação, após a aplicação de $\mathrm{N}$ em pré-semeadura no milho e posterior semeadura, o maquinário fica disponível aos tratos culturais destinados à cultura da soja, que ocupa a maior porcentagem das áreas.

No sentido de melhor entender o comportamento do $\mathrm{N}$ na cultura do milho em SSD, alguns trabalhos vêm sendo desenvolvidos, utilizando o isótopo ${ }^{15} \mathrm{~N}$ (Lara Cabezas et al., 2004; Lara Cabezas et al., 2005; Gava et al., 2006). Porém há carência de informação em relação à aplicação em pré-semeadura, a um sistema que considere dois anos de soja como antecessora ao milho e, principalmente, ao aproveitamento do $\mathrm{N}$ em solos com textura média, cultivados com soja previamente, já que esta é responsável por enriquecer o solo com $\mathrm{N}$ após seu cultivo (Araújo et al., 2004).

Este estudo teve por objetivo avaliar a influência da época de aplicação do nitrogênio suplementar à adubação de semeadura na produtividade de palha da planta de cobertura, nas concentrações foliares de nitrogênio, fósforo, potássio, cálcio, magnésio e enxofre e na produtividade de grãos do milho após dois anos de cultivo de soja em solo de textura média, além de quantificar a recuperação do nitrogênio do sulfato de amônio e da uréia.

\section{MATERIAL E MÉTODOS}

O trabalho foi desenvolvido entre abril de 2002 e abril de 2003 no município de Uberlândia (Minas Gerais), em um Latossolo Vermelho-Amarelo (LVA), textura média (205 $\mathrm{g} \mathrm{kg}^{-1}$ de argila), situado a 1852,3'S e 48²4,895’ W, a 830 $m$ de altitude, com histórico de quatro anos sob SSD. Antes da semeadura do milho, o solo apresentava a seguinte caracterização química: $\mathrm{pH}_{\text {(água) }}, 6,0 ; \mathrm{P}_{\text {(Mehlich) }}, 30,4 \mathrm{mg} \mathrm{dm}^{-}$ 3; $\mathrm{K}_{\text {(Mehlich) }}, 56,2 \mathrm{mg} \mathrm{dm}^{-3}$; Ca, 1,2 $\mathrm{cmol}_{\mathrm{c}} \mathrm{dm}^{-3} ; \mathrm{Mg}, 0,4 \mathrm{cmol}_{\mathrm{c}}$ $\mathrm{dm}^{-3}$; Al, 0,0 $\mathrm{cmol}_{\mathrm{c}} \mathrm{dm}^{-3}$; S, 3,8 $\mathrm{mg} \mathrm{dm}^{-3}$; CTC a pH 7,0, 3,8 $\mathrm{cmol}_{\mathrm{c}} \mathrm{dm}^{-3} ; \mathrm{V}, 45 \%$ e $\mathrm{MO}, 19 \mathrm{~g} \mathrm{~kg}^{-1}$ para a camada de $0-0,2$ $\mathrm{m}$ de profundidade.

Após a colheita da soja, em 13/4/2002, semeou-se o milheto (var. BN-2), como planta de cobertura em toda área experimental. Nesta ocasião foram instalados sete tratamentos com três repetições em delineamento inteiramente casualizado, totalizando 21 parcelas de 100 x 5 m cada. O manejo adotado para a aplicação do N (110 kg ha-1), como dose suplementar à adubação de semeadura $\left(44 \mathrm{~kg} \mathrm{ha}^{-1}\right)$ na cultura do milho, foi: T1: 00-00-00-00; T2: 110-00-00-00; T3: 45-00-65-00; T4: 00-45-65-00; T5: 20-00-70-20, T6:00-00-90-20, T7:00-00-90 UR 20, cuja sequência para cada tratamento corresponde à quantidade de $\mathrm{N}$ em $\mathrm{kg} \mathrm{ha}^{-1}$ aplicado na semeadura do milheto antes da semeadura do milho (5 dias)- cobertura (5-7 folhas) - cobertura (9-10 folhas). A aplicação do N suplementar à semeadura seguiu o seguinte procedimento: semeadura do milheto, incorporado abaixo e ao lado das sementes, com o auxílio de uma semeadora; antes da semeadura do milho, em faixas distanciadas entre si $0,37 \mathrm{~m}$, na superfície; cobertura (5-7 folhas)- incorporado a 0,05-0,07 $\mathrm{m}$ de profundidade, no espaçamento de 0,37 m entrelinhas, lado a lado da planta de milho; cobertura (9-10 folhas, aplicado na superfície do solo, no espaçamento de $0,75 \mathrm{~m}$, na entrelinha do milho, aproximadamente a 0,2-0,3 m das plantas de milho. Como fonte de $\mathrm{N}$ suplementar à semeadura, utilizou-se o sulfato de amônio (SA), com 20\% de N em todos os tratamentos, com exceção do T7, em que $90 \mathrm{~kg}$ de $\mathrm{N}$ foram da fonte uréia (UR) com 45\% de N. O tratamento T7 representou o manejo adotado pelo produtor. A aplicação de fertilizante incorporado no estádio de 5-7 folhas (SA ou UR) foi realizada com o motivo de padronizar o possível dano ao sistema radicular, já que a UR deve ser incorporada para reduzir perdas de $\mathrm{N}_{-} \mathrm{NH}_{3}$ (Lara Cabezas et al., 2000).

Em setembro realizou-se a amostragem do milheto semeado em abril. Para isto foram amostradas todas as plantas contidas em seis metros lineares dentro de cada parcela. Na primeira semana de novembro de 2002 realizou-se a dessecação de todo o talhão do experimento (2,4-D: 406 g ha-1 e glifosate: $1.080 \mathrm{~g} \mathrm{ha}^{-1} \mathrm{em} 150 \mathrm{~L} \mathrm{ha}^{-1}$ de água). Um dia antes de semear o milho amostrou-se todo material vegetal que cobria o solo (cobertura morta e viva), utilizando o método do quadrado $\left(1 \mathrm{~m}^{2}\right)$, o qual foi lançado aleatoria- 
mente dentro de cada parcela três vezes, para quantificar a cobertura antes da semeadura do milho. O milho - híbrido simples Fort (precoce) - foi semeado em 6/11/02, no espaçamento de $0,75 \mathrm{~m}$ entre linhas, para uma população de 64.000 plantas ha-1. A adubação de base do milho consistiu na aplicação de $550 \mathrm{~kg} \mathrm{ha}^{-1}$ da fórmula 08-20-10.

A emergência das plantas ocorreu cinco dias após a semeadura e, em 23/11, aplicou-se pós-emergente, inseticida e fertilizante foliar em todo o experimento, utilizando a mistura de nicosulfuron (376 $\left.\mathrm{g} \mathrm{ha}^{-1}\right)$, lufenuron (10 $\left.\mathrm{g} \mathrm{ha}^{-1}\right)$, óleo mineral (0,7 L ha' $a^{-1}$, Mn (198 $\left.\mathrm{g} \mathrm{ha}^{-1}\right)$, S (97,5 $\left.\mathrm{g} \mathrm{ha}^{-1}\right)$, B (67,5 $\left.\mathrm{g} \mathrm{ha}^{-1}\right)$, atrazine (1.940 $\mathrm{g} \mathrm{ha}^{-1}$ ) em $200 \mathrm{~L} \mathrm{ha}^{-1} \mathrm{em}$ todo o experimento. A amostragem das folhas do milho foi realizada na primeira semana de janeiro de 2003 (florescimento), com a coleta da folha abaixo e oposta a espiga, em número de 15 folhas por parcela, analisadas segundo Malavolta et al. (1997). Em 17/3/2003, avaliou-se a produtividade de grãos (umidade de $130 \mathrm{~g} \mathrm{~kg}^{-1}$ ), em $30 \mathrm{~m}$ lineares (três linhas de $10 \mathrm{~m}$ ). Em todas as amostragens, o material foi seco em estufa a $65^{\circ} \mathrm{C}$ até peso constante e foi, em seguida, moído finamente.

Durante a aplicação do fertilizante comercial, interrompeu-se a operação para a introdução de microparcelas de $1,5 \mathrm{~m}$ e, neste espaço, aplicou-se fertilizante enriquecido com ${ }^{15} \mathrm{~N}(*)$, em quatro tratamentos, a saber: T4:00-45*65*-00; T5:20-00-70*-20*, T6:00-00-90*-20*, T7:00-00$90 *$ UR $-20 *$. Utilizou-se sulfato de amônio- SA- ${ }^{15} \mathrm{~N}$ (concentração isotópica $=3,09 \pm 0,02 \%$ át. $\left.{ }^{15} \mathrm{~N}\right)$ e uréia $(3,01 \pm 0,02 \%$ de átomos ${ }^{15} \mathrm{~N}$ ), obedecendo-se à dose, proporção entre fontes e modo de aplicação como no restante do experimento. Para a determinação da eficiência de recuperação do nitrogênio $\left({ }^{15} \mathrm{~N}\right)$, colheram-se as plantas inteiras (acima do solo) em $1 \mathrm{~m}$ linear. Para as épocas de aplicação - présemeadura e cobertura (5-7 folhas)- foi colhida a linha central e as duas linhas laterais à aplicação (central separadamente das laterais); para a cobertura (9-10 folhas) foram colhidas as duas linhas paralelas à linha de aplicação. Os cálculos de recuperação estão descritos a seguir:

a) Porcentagem de nitrogênio na planta proveniente do fertilizante (\%NPPF)

Obtidas as porcentagens de átomos de ${ }^{15} \mathrm{~N}$ na planta e no fertilizante, usou-se a equação 1 , obtida pelo princípio da diluição isotópica, para cálculo da \%NPPF.

$$
\begin{gathered}
\% N P P F=\frac{\%{ }^{15} \mathrm{~N} \text { amostra }-\%{ }^{15} \mathrm{~N} \text { ab. natural }}{\%{ }^{15} \mathrm{~N} \text { fertilizante }-\%{ }^{15} \mathrm{~N} \text { ab. natural }} x 100 \\
\text { Equação (1) }
\end{gathered}
$$

em que:

$\%{ }^{15} \mathrm{~N}$ amostra = abundância em \% de átomos de ${ }^{15} \mathrm{~N}$ na planta; $\%{ }^{15} \mathrm{~N}$ ab. natural = abundância natural em \% de átomos de ${ }^{15} \mathrm{~N}$ na planta que não foi fertilizada; $\%{ }^{15} \mathrm{~N}$ fertilizante $=$ abundância em \% de átomos de ${ }^{15} \mathrm{~N}$ no fertilizante. b) Nitrogênio Total Acumulado (NTA)

$\mathrm{NTA}=\frac{\mathrm{N} \times \mathrm{MS}}{1000}$

Equação (2)

em que:

NTA = nitrogênio total acumulado $\left(\mathrm{kg} \mathrm{ha}^{-1}\right) ; \mathrm{N}=$ concentração de nitrogênio na amostra $\left(\mathrm{g} \mathrm{kg}^{-1}\right)$; MS = massa de material seco da amostra (kg ha-1).

c) Quantidade de nitrogênio na planta proveniente do fertilizante (NPPF) em kg ha-1

$$
\begin{aligned}
& \mathrm{NPPF}=\frac{\% N P P F \times N T A}{100} \quad \text { Equação (3) } \\
& \text { em que: }
\end{aligned}
$$

$\% \mathrm{NPPF}=$ porcentagem de $\mathrm{N}$ na planta proveniente do fertilizante.

d) Eficiência de recuperação do fertilizante nitrogenado (\%ERFN)

ERFN $=\frac{N P P F}{Q N A} x 100$

Equação (4)

em que:

QNA = Quantidade de nitrogênio aplicado como fertilizante marcado $\left(\mathrm{kg} \mathrm{ha}^{-1}\right)$; ERFN = significa a porcentagem de $\mathrm{N}$ que foi aproveitado do total de fertilizante aplicado.

As análises de abundância de ${ }^{15} \mathrm{~N}$ do material enriquecido foram feitas em espectrômetro de massa automatizado modelo ANCA-SL (Barrie \& Prosser, 1996).

Os resultados foram submetidos à análise de variância. As causas de variação significativas, relacionadas à cultura do milho, foram comparadas pelo teste de F para contrastes ortogonais a 5 e $10 \%$ de probabilidade, utilizandose o programa SAS.

\section{RESULTADOS E DISCUSSÃO}

Na região é comum a seca entre os meses de maio a julho, sendo que no presente ano houve ausência total de chuvas, com as primeiras precipitações ocorrendo em setembro (34 mm) e outubro (31 mm), estimulando a germinação de algumas espécies de plantas espontâneas, que aumentaram a cobertura vegetal sobre o solo no período de primavera. Antes da semeadura do milho (11/2002), a superfície do solo apresentava cerca de 3,37 t ha-1 de massa de matéria seca (MMS), representada por uma diversidade de restos de plantas espontâneas, restos de soja e por plantas espontâneas que vegetavam, como destaque para o timbete (Cenchrus echinatus), além de braquiárias. O milheto que foi semeado em abril, como planta de cobertura, não resultou em ganhos expressivos de massa, pois sua produtividade não ultrapassou 120 kg ha $^{-1}$, resultado do déficit hídrico. 
A aplicação de $110 \mathrm{~kg} \mathrm{ha}^{-1}$ de $\mathrm{N}$ complementares à adubação de semeadura resultou em aumento da produtividade e das concentrações de $\mathrm{N}$ e $\mathrm{P}$ nas folhas em relação aplicação de somente de $44 \mathrm{~kg} \mathrm{ha}^{-1}$ de $\mathrm{N}$ na semeadura (Tabela 1 , contraste 1 ). A aplicação de $\mathrm{N}$ suplementar à semeadura resultou no incremento de $1,21 \mathrm{t} \mathrm{ha}^{-1}$ de grãos, ou seja, ganho de aproximadamente $11,0 \mathrm{~kg}$ de grãos para cada kg de $\mathrm{N}$ aplicado na cobertura, sem admitir a real recuperação do $\mathrm{N}$ aplicado. Escosteguy et al. (1997) também observaram aumento na produtividade do milho quando aplicaram 80 ou 160 $\mathrm{kg} \mathrm{ha}^{-1}$ de $\mathrm{N}$ em cobertura, parcelados ou não, em relação ausência desta, em SSD. Resultados semelhantes foram observados por Basso e Ceretta (2000), porém, estes autores omitiram totalmente a aplicação de $\mathrm{N}$ na testemunha. Isto demonstra que a disponibilidade de $\mathrm{N}$ mineral às plantas em solo de textura média, após o cultivo de dois anos de soja, não foi suficiente para atender à demanda da cultura, havendo a necessidade da aplicação de $\mathrm{N}$ suplementar, resultado este, divergente do observado em solo de textura argilosa, para a mesma safra, na região (Lange et al., 2008).

Para o parcelamento observou-se maior eficiência quando foi realizada a aplicação em duas em épocas (4500-65-00 e 00-45-65-00) ou três épocas (20-00-70-20) dividindo-se a dose de forma mais homogênea em relação à aplicação de maiores doses numa única época (110-0000-00) ou duas (00-00-90-20), com ganho de $1,17 \mathrm{tha}^{-1} \mathrm{de}$ grãos (contraste 2). Segundo Fancelli \& Dourado Neto (2004), o potencial de produção do milho é definido precocemente, na emissão da $4^{\mathrm{a}}$ a $6^{\mathrm{a}}$ folha e a confirmação do número de fileiras entre a $7^{\mathrm{a}}$ e $9^{\mathrm{a}}$ folha completamente expandidas. Assim, a aplicação de parte do fertilizante antes da semeadura, para os tratamentos acima apontados, pode disponibilizar mais $\mathrm{N}$ para a cultura no período pós-emergência, uma vez que o $\mathrm{N}$ aplicado na semeadura pode ter sido imobilizado, pois a superfície do solo apresentava 3,37 t ha-1 de resíduos com relação C/N igual a 31. Além disso, fertilizantes nitrogenados provocam queda do pH e alteração no índice salino do solo, aumentando a pressão osmótica da solução (Malavolta et al., 2002), o que pode ter prejudicado a cultura quando se aplicou $90 \mathrm{~kg} \mathrm{ha}^{-1}$ de $\mathrm{N}$ em uma única operação a 20 $\mathrm{cm}$ da linha de semeadura, em um solo com apenas $205 \mathrm{~g}$ $\mathrm{kg}^{-1}$ de argila.

Quando $90 \mathrm{~kg} \mathrm{ha}^{-1}$ de N da UR ou SA foram aplicados no estádio de 5-7 folhas, não se observou diferença para nenhuma das variáveis estudadas, apesar do aumento de 0,78 tha $^{-1}$ de grãos para a aplicação de SA.

A concentração foliar de $\mathrm{N}$ variou entre 33 e $38 \mathrm{~g} \mathrm{~kg}^{-1}$, sendo os valores considerados acima do adequado para a cultura (Martinez et al., 1999). Mesmo na ausência de N complementar à semeadura os resultados foram adequados, o que se deve a um efeito de concentração ou do próprio genótipo utilizado. O mesmo foi observado na concentração de P quando se comparou a média dos tratamentos testados e a testemunha. Segundo Bull (1993) existe interação entre $\mathrm{N}$ e $\mathrm{P}$ e, mesmo em solos com elevados teores de P, é marcante a influência do N, em função do aumento do sistema radicular.

A concentração de S é adequada, até mesmo na ausência da aplicação de $\mathrm{N}$ suplementar, variando entre 1,7 e $2,4 \mathrm{~g} \mathrm{~kg}^{-1}$. Houve ainda aumento na concentração deste nutriente em outras formas de parcelamento (contrastes 3 e 6). Os resultados indicam, possivelmente, um menor aproveitamento do $\mathrm{S}$ do sulfato de amônio (SA) quando

Tabela 1. Contrastes para concentração foliar de nitrogênio (N), fósforo (P), potássio (K), cálcio (Ca), magnésio (Mg) e enxofre (S), e produtividade de grãos na cultura do milho em sucessão a dois anos de cultivo de soja, em solo de textura média, em relação a diferentes épocas de parcelamento da adubação nitrogenada, em sistema semeadura direta no Cerrado

\begin{tabular}{|c|c|c|c|c|c|c|c|}
\hline \multirow{2}{*}{ Contraste $^{(1)}$} & \multirow{2}{*}{$\begin{array}{c}\text { Produtividade } \\
\left(\text { t ha }^{-1}\right)\end{array}$} & $\mathbf{N}$ & $\mathbf{P}$ & $\mathbf{K}^{\mathrm{ns}}$ & Ca & $\mathbf{M g}^{\mathrm{ns}}$ & $S$ \\
\hline & & \multicolumn{6}{|c|}{$\mathrm{g} \mathrm{kg}^{-1}$} \\
\hline 1.T1 vs Demais & $6,22 \times 7,43^{* *}$ & $33 \times 36 * *$ & $3,3 \times 3,6 * *$ & $25 \times 26$ & $1,6 \times 1,7$ & $1,8 \times 1,7$ & $1,9 \times 2,1$ \\
\hline $\begin{array}{l}\text { 2.T2;T6;T7 vs } \\
\text { T3;T4;T5 }\end{array}$ & 6,85 x 8,02** & 36 x 37 & 3,5 x 3,6** & $25 \times 27$ & $2,0 \times 1,5 * *$ & $1,7 \times 1,7$ & $2,0 \times 2,1$ \\
\hline 3.T2 vs T6;T7 & $6,78 \times 6,89$ & $35 \times 36$ & $3,4 \times 3,5$ & $24 \times 26$ & $1,6 \times 2,2^{*}$ & $1,6 \times 1,8$ & $1,7 \times 2,1 * *$ \\
\hline 4.T6 vs T7 & $7,28 \times 6,50$ & 35 x 37 & $3,6 \times 3,4$ & $25 \times 26$ & $1,9 \times 2,4$ & $1,9 \times 1,7$ & $2,2 \times 2,0$ \\
\hline 5.T5 vs T3;T4 & 8,15 x 7,96 & 37 x 37 & $3,7 \times 3,6$ & $26 \times 27$ & $1,6 \times 1,4$ & $1,7 \times 1,7$ & $2,2 \times 2,1$ \\
\hline 6. T3 vs T4 & $7,76 \times 8,15$ & 38 x 35* & $3,5 \times 3,7 *$ & $27 \times 27$ & $1,1 \times 1,7$ & $1,5 \times 1,9$ & $1,8 \times 2,4^{* *}$ \\
\hline Média & 7,26 & 35,8 & 3,5 & 25,8 & 1,7 & 1,7 & 2,0 \\
\hline CV\% & 12,5 & 6,5 & 4,6 & 8,3 & 24,7 & 18,7 & 10,0 \\
\hline Concentr. $^{(2)}$ & & $27,5-32,5$ & $2,5-3,5$ & $17,5-22,5$ & $2,5-4,0$ & $2,5-4,0$ & $1-2$ \\
\hline
\end{tabular}

${ }^{(1)}(\mathrm{T} 1): 00-00-00-00$; (T2): 110-00-00-00; (T3): 45-00-65-00; (T4): 00-45-65-00; (T5): 20-00-70-20; (T6): 00-00-90-20; (T7): 00$00-90^{\text {UR }}-20$, cuja sequência em cada tratamento corresponde à quantidade de $\mathrm{N}$ em $\mathrm{kg} \mathrm{ha}^{-1}$, aplicada na semeadura do milheto; 5 dias antes da semeadura do milho; em cobertura quando as plantas estavam com 5 a 7 folhas; em cobertura quando as plantas estavam com 9 a 10 folhas. ${ }^{(2)}$ Concentrações de nutrientes na folha do milho, consideradas adequadas para o Estado de Minas Gerais (Martinez et al., 1999).

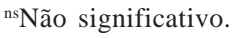


uma parte ou todo o fertilizante é aplicado antecipadamente, na semeadura da planta de cobertura. Em relação às diferentes fontes de $\mathrm{N}$ (contraste 4), não se verificou diferença significativa nas concentrações foliares, apesar de os valores serem superiores quando se utilizou somente SA em relação à mistura UR e SA. Neste caso, a aplicação de $20 \mathrm{~kg} \mathrm{ha}^{-1}$ de N, na forma de SA, estádio de 910 folhas, com o concomitante fornecimento de $24 \mathrm{~kg}$ ha${ }^{1}$ de $\mathrm{S}$, supriu as plantas em enxofre.

Embora tenha existido efeito significativo dos tratamentos sobre a concentração foliar de Ca em alguns tratamentos (contraste 2 e 3), os teores estão abaixo do considerado adequado para cultura (Martinez et al., 1999), assim como os de Mg. Provavelmente os baixos teores no solo antes da semeadura do milho explicam este comportamento. Salienta-se, entretanto, que as calibrações de nutrientes no solo e foliares foram dimensionadas, em sua maioria, em experimentos sob SPC. No SSD, a dinâmica de nutrientes, a variabilidade horizontal e vertical diferem, o que pode também diferenciar a sua disponibilidade. A maior concentração de nutrientes na camada superficial do solo em SSD pode influenciar na nutrição da cultura (Muzilli, 1983), além da variabilidade genética do hibrido, já que sintomas visuais de deficiência não foram constatados. Em média 48\% do $\mathrm{N}$ aplicado em cobertura ou em pré-semeadura foi recuperado, não havendo diferença significativa entre os tratamentos, para o parcelamento de $110 \mathrm{~kg} \mathrm{ha}^{-1}$ de $\mathrm{N}$, nos diferentes compartimentos da planta (Tabela 2). Admitindo a recuperação acima citada ( 52,8 $\mathrm{kg})$ e que houve um ganho em produtividade de $1.210 \mathrm{~kg}$ em relação a testemunha, na média dos tratamentos, podese estimar que cada kg de $\mathrm{N}$ aplicado e recuperado houve aumento de 22,9 kg de grãos.

Verificou-se ainda que 33\% do total de $\mathrm{N}$ na planta eram provenientes do fertilizante (PNPDF) aplicado como dose suplementar à adubação de semeadura e o restante procedeu de outras fontes, inclusive do $\mathrm{N}$ aplicado na semeadura. Com relação à distribuição do $\mathrm{N}$ nos diferentes compartimentos da planta, $70 \%$ do $\mathrm{N}$ recuperado alocou-se nos grãos e 30\% na palha (15-16 kg de N), quantidade esta que retorna ao sistema, podendo ser aproveitada, em parte, pela cultura sucessora, juntamente com parte do $\mathrm{N}$ residual que não foi absorvido. Os resultados de distribuição nos diferentes compartimentos da planta são semelhantes aos observados por Gava et al. (2006) e Silva et al (2006), sendo que os autores observaram ERFN próxima a 50\%.

Em relação à recuperação apenas dos $90 \mathrm{~kg} \mathrm{ha}^{-1}$ de $\mathrm{N}$ (Tabela 2), constatou-se diferença significativa em relação à ERFN nos grãos, na palha e na planta toda (contraste 7, 9, 10 e 11, respectivamente). O parcelamento de sulfato de amônio (SA) em duas épocas aumentou a ERFN em relação a uma única aplicação (contraste 10). Já para as fontes estudadas (contraste 7, 9 e 11), houve menor recuperação do N-UR em relação ao N-SA. Entre os fatores que podem ter provocado menor recuperação do NUR, pode-se destacar uma possível maior imobilização do N-UR em relação ao N-SA (Lara Cabezas et al., 2005); o maior índice salino da UR (75) em relação ao SA (69), pode ter provocado danos ao sistema radicular da cultura, uma possível lixiviação da UR, evento não muito comum, mais documentado por Suhet et al. (1985), e que pode ter ocorrido, em função das elevadas precipitações (Figura 1). Segundo Cantarella \& Duarte (2004), hoje altas doses de $\mathrm{N}$ são aplicadas na cultura do milho e a possibilidade de perdas por lixiviação, principalmente em solos arenosos, não pode ser descartada. Além disso, a UR, ao ser aplicada no solo, pode não hidrolisar-se tão rapidamente, pois é uma molécula neutra, o que estaria favorecendo a lixiviação, principalmente na condição de chuvas intensas, como as que ocorrem na região. A menor recuperação total do N-UR teve como reflexo a redução na produtividade de grãos, com queda de $0,78 \mathrm{t} \mathrm{ha}^{-1}$ em relação ao sulfato de amônio (Tabela 1, contraste 4).

De modo geral a cultura acumulou, em média, $157 \mathrm{~kg}$ ha $^{-1}$ de N (Tabela 2). Destes, $52 \mathrm{~kg} \mathrm{ha}^{-1}$ procederam do fertilizante aplicado como dose suplementar à semeadura. Admitindo-se que a cultura tenha recuperado ainda 50\% do $\mathrm{N}$ aplicado na semeadura ( $22 \mathrm{~kg} \mathrm{ha}^{-1}$ ), tem-se um total de $74 \mathrm{~kg} \mathrm{ha}^{-1}$ de $\mathrm{N}(52+22)$ na planta inteira, proveniente do fertilizante aplicado na corrente safra. O restante (83 $\mathrm{kg} \mathrm{ha}^{-1}$ ), é de origem do solo, entre elas a decomposição de resíduos, a fixação biológica, os resíduos de fertilizações anteriores, o que demonstra o potencial do solo, quando manejado em sistema de semeadura direta, em fornecer de $\mathrm{N}$ para as culturas, além do efeito do $\mathrm{N}$ residual da soja (Araújo et al., 2004). Isto também ficou evidente no tratamento que recebeu $\mathrm{N}$ somente na semeadura, o qual produziu 6,22 t ha-1 de grãos com apenas $44 \mathrm{~kg} \mathrm{ha}^{-1}$ de $\mathrm{N}$ aplicados. Essa produtividade deve-se também as condições adequadas de clima, com boa distribuição de chuvas e temperatura adequada durante todo o ciclo da cultura (Figura 1).

Ou ponto importante destaca-se em relação à aplicação antecipada (45 kg ha ${ }^{-1}$ de $\mathrm{N}$ em pré-semeadura, tratamento 00-45-65-00). Neste a recuperação foi baixa (26\%), com aproveitamento de apenas $12 \mathrm{~kg} \mathrm{ha}^{-1}$, corroborando com Lara Cabezas et al. (2004, 2005) que verificaram, em alguns casos, recuperação de apenas 28\% para a aplicação em pré-semeadura. A baixa ERFN nesta condição, em relação às demais épocas de aplicação, deveu-se à textura do solo (762 $\mathrm{g} \mathrm{kg}^{-1}$ de areia) aliada à pluviosidade, que podem ter favorecido a lixiviação de $\mathrm{N}$, pois no intervalo entre a aplicação antecipada e a primeira cobertura (30 dias), acumulou-se $175 \mathrm{~mm}$ de chuvas, com precipitações 
diárias de até $40 \mathrm{~mm} \mathrm{dia}^{-1}$ (Figura 1). Bortolini et al. (2001) e Pottker \& Wietholter (2004) também relatam resultados semelhantes. Segundo Cantarella \& Duarte (2004), a antecipação pode ser uma prática pouco segura em solos arenosos, pois é arriscado contar com a imobilização do N na fração orgânica, não existindo evidências experimentais sobre o assunto. Portanto, para a opção de manejo 00-4565-00, a aplicação em cobertura foi determinante na ERFN total, pois dos $52 \mathrm{~kg} \mathrm{ha}^{-1}$ recuperados pela cultura, $40 \mathrm{~kg}$ ha $^{-1}$ foram absorvidos do $\mathrm{N}$ aplicado em cobertura. Assim, a prática da adubação nitrogenada em solos de textura média a arenosa deve ser antecipada.

Tabela 2. Contrastes calculados de nitrogênio $\left(\mathrm{kg} \mathrm{ha}^{-1}\right)$ na planta, proveniente do fertilizante (NPPF), eficiência (\%) de recuperação do fertilizante nitrogenado (ERFN), porcentagem de nitrogênio derivado do fertilizante ${ }^{15} \mathrm{~N}$ na planta (PNDF), na colheita do milho em sucessão a dois anos de cultivo de soja, em relação a diferentes épocas de parcelamento da adubação nitrogenada, em solo de textura média, em sistema semeadura direta no Cerrado ${ }^{(1)}$

\begin{tabular}{|c|c|c|c|c|c|}
\hline \multirow{3}{*}{ Contraste $^{(2)}$} & \multicolumn{4}{|c|}{ Dose: $110 \mathrm{~kg} \mathrm{ha}^{-1}$ de $\mathrm{N}$} & \multirow[b]{2}{*}{ NDOF } \\
\hline & ${ }^{(1)} \mathrm{N}$-total & NPPF & ERFN & PNDF & \\
\hline & \multicolumn{2}{|c|}{ kg ha $^{-1}$} & \multicolumn{2}{|c|}{$\%$} & kg ha $^{-1}$ \\
\hline 1. T4 vs T6,T7 & $124 \times 102$ & $36 \times 37$ & Grãos & $29 \times 36$ & $88 \times 65$ \\
\hline 2. T6 vs T7 & $102 \times 101$ & $40 \times 33$ & 37 x30 & $39 \times 33$ & $62 \times 68$ \\
\hline Média & 109 & 36 & 33 & 33 & 73 \\
\hline CV(\%) & $-(3)$ & 17 & Palha & - & - \\
\hline 3. T4 vs T6,T7 & $58 \times 42$ & $17 \times 16$ & $15 \times 14$ & $31 \times 37$ & $41 \times 27$ \\
\hline 4. $\mathrm{T} 6$ vs $\mathrm{T} 7$ & $39 \times 45$ & $16 \times 15$ & $14 \times 14$ & $40 \times 34$ & $23 \times 30$ \\
\hline Média & 48 & 16 & 14 & 34 & 32 \\
\hline CV(\%) & - & 13 & 13 & - & - \\
\hline 5. T4 vs T6,T7 & $182 \times 144$ & $\begin{array}{l}52 \times 52 \\
\end{array}$ & Planta inteira & $30 \times 36$ & $130 \times 92$ \\
\hline 6. T6 vs T7 & $142 \times 146$ & $56 \times 49$ & $51 \times 44$ & $40 \times 33$ & $86 \times 98$ \\
\hline Média & 157 & 52 & 48 & 33 & 105 \\
\hline CV(\%) & - & 14 & 14 & - & - \\
\hline
\end{tabular}

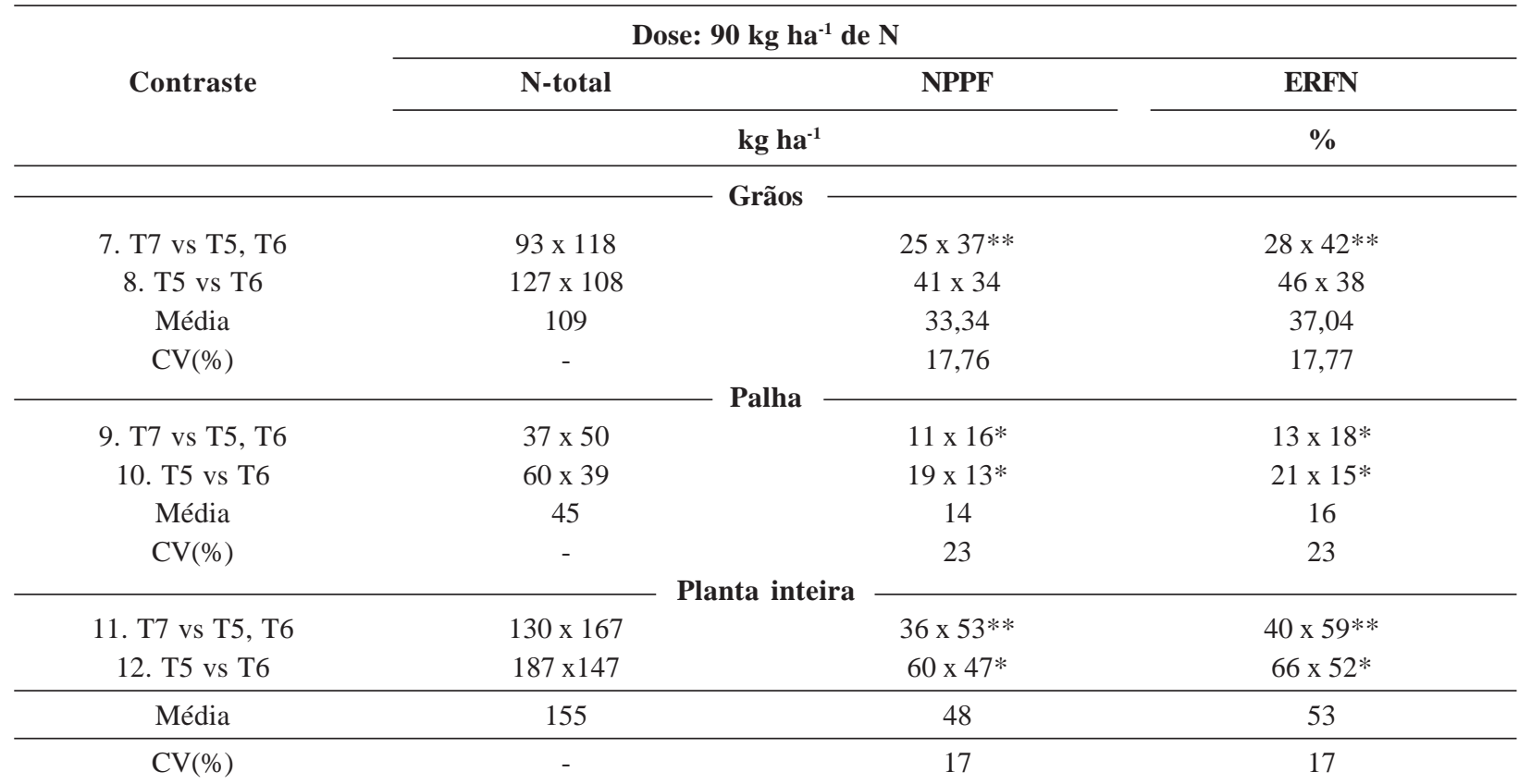

${ }^{(1)} \mathrm{N}$-total: nitrogênio total acumulado, NDOF: nitrogênio derivado de outras fontes, além do ${ }^{15} \mathrm{~N}$ estudado (adubação de base, $\mathrm{N}$ não enriquecido, solo e outras fontes). ${ }^{(2)}(\mathrm{T} 4)$ : $00-45^{15 \mathrm{~N}}-65^{15 \mathrm{~N}}-00$; (T5): $20-00-70^{15 \mathrm{~N}}-20^{15 \mathrm{~N}}$; (T6): 00-00-90 $15 \mathrm{~N}-20^{15 \mathrm{~N}}$; (T7): $00-00-90^{\mathrm{UR} 15 \mathrm{~N}}-20^{15 \mathrm{~N}}$ cuja sequência em cada tratamento corresponde à quantidade de $\mathrm{N} \mathrm{em} \mathrm{kg} \mathrm{ha-1}$, aplicada na semeadura do milheto; 5 dias antes da semeadura do milho; em cobertura quando as plantas estavam com 5 a 7 folhas; em cobertura quando as plantas estavam com 9 a 10 folhas. UR: uréia; demais tratamentos: Sulfato de amônio. ${ }^{(3)}$ Não foi realizada a análise estatística para N-total, PNDF e NDOF. * * **: significativo a $10 \%$ e $5 \%$, respectivamente. 


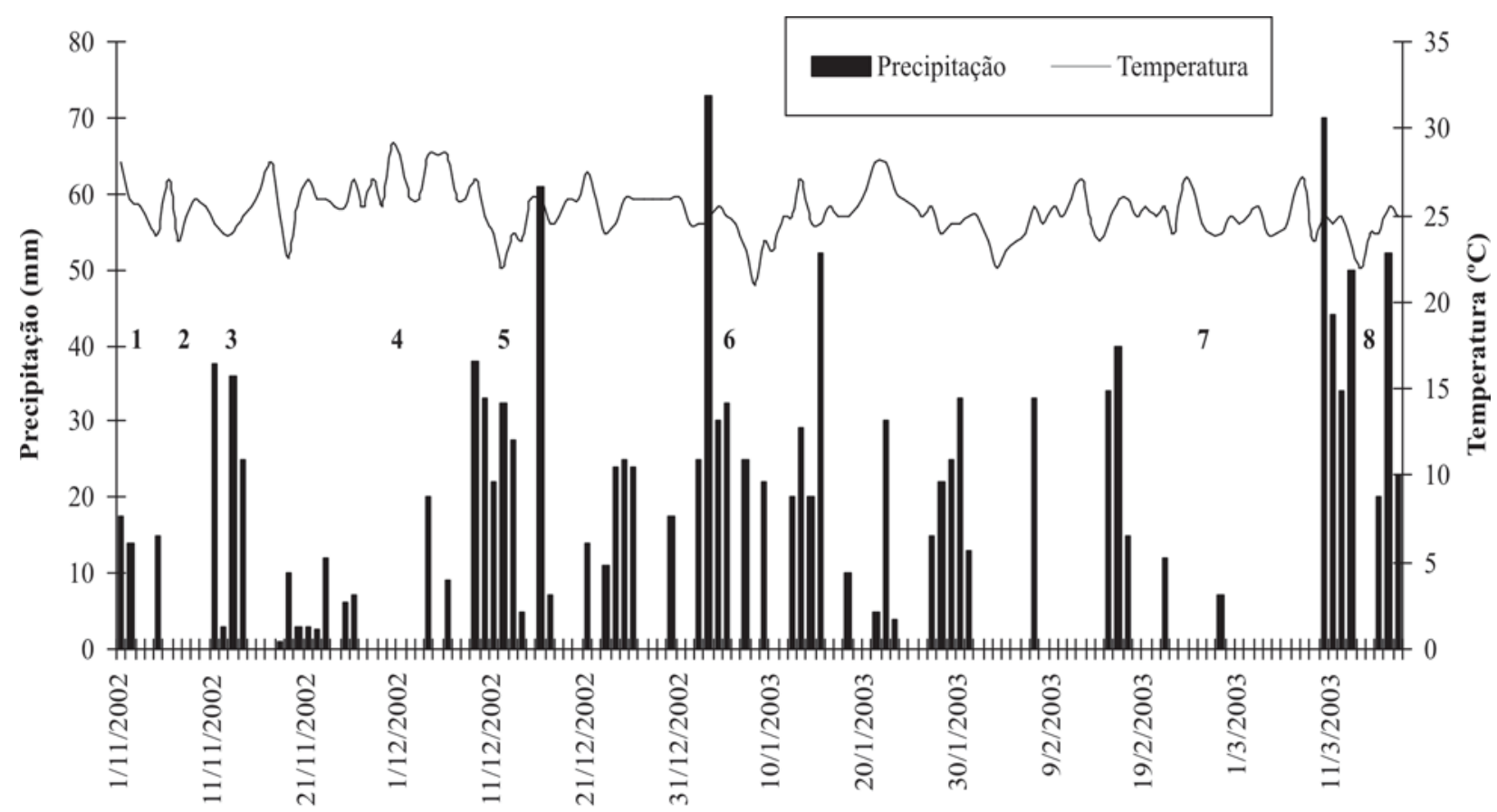

Figura 1. Temperatura média diária do ar e precipitação pluvial, durante o desenvolvimento do milho em sucessão a dois anos de cultivo de soja, em solo de textura média, na região do Cerrado. Precipitação mensal acumulada durante o ciclo da cultura: novembro (192 mm), dezembro (370 mm), janeiro (486 mm), fevereiro (141 mm) e março (293 mm). Legenda: 1- N em pré-semeadura (2/11/ 2002); 2- semeadura (7/11/2002); 3- emergência (12/11/2002); 4- N em cobertura 5-7 folhas (2/12/2002); 5- N em cobertura 9-10 folhas (13/12/2002); 6- florescimento e análise foliar (4/1/2003); 7- ponto de maturidade fisiológica (27/2/2003); 8-colheita (17/3/ 2003).

\section{CONCLUSÕES}

A adubação nitrogenada suplementar à semeadura, aplicada em diferentes épocas, altera a produtividade de grãos e as concentrações foliares de nitrogênio, fósforo, cálcio e enxofre;

A adubação nitrogenada suplementar à semeadura, aplicada em duas épocas no milho, pré-semeadura e cobertura ou em duas coberturas, não altera a recuperação do fertilizante; porém, a aplicação em cobertura é fundamental em aumentar a eficiência de utilização, para altas doses de $\mathrm{N}$;

A recuperação do nitrogênio da fonte sulfato de amônio aplicado em cobertura é superior a da uréia para a mesma dose;

O parcelamento de sulfato de amônio em cobertura melhora a recuperação do fertilizante na palha e na planta inteira em relação à aplicação apenas em uma época.

\section{AGRADECIMENTOS}

À Fundação Agrisus, ao SN-Centro de Pesquisa e Promoção de Sulfato de Amônio Ltda., aos proprietários da Fazenda Canadá, ao CENA/USP pela realização das análises isotópicas; ao CNPq (CTHidro) pela concessão da bolsa de estudos.

\section{REFERÊNCIAS}

Aita C, Ceretta CA, Thomas Al, Pavinato A \& Bayer C (1994) Espécies de inverno como fonte de nitrogênio para o milho no sistema de cultivo mínimo e feijão em plantio direto. Revista Brasileira de Ciência do Solo, 18: 101-108.

Araújo ES, Medeiros AFA, Dias FC, Urquiaga S, Boddey RM \& Alves BJR (2004) Quantificação do N do solo derivado das raízes da soja utilizando o isótopo ${ }^{15} \mathrm{~N}$. Revista Universidade Rural, 24: 7-12.

Barrie A \& Prosser SJ (1996) Automated analysis of light-element stable isotopes by isotope ratio mass spectrometry. In: Boutton Tw, Yamasaki S (Ed.). Mass spectrometry of soils. New York: Marcel Dekker, p.1-46.

Basso CJ \& Ceretta CA (2000) Manejo do nitrogênio em sucessão a plantas de cobertura de solo, sob plantio direto. Revista Brasileira de Ciência do Solo, 24: 905-915.

Borket CM, Glaudênico CA, Pereira JE, Pereira LR \& Oliveira Junior A (2003). Nutrientes minerais na biomassa da parte aérea em culturas de cobertura de solo. Pesquisa Agropecuária Brasileira, 38: 143-153.

Bortolini CG, Silva PRF, Argenta G \& Forsthofer EL (2001) Rendimento de grãos de milho cultivado após aveia-preta em resposta a adubação nitrogenada e regime hídrico. Pesquisa Agropecuária Brasileira, 36: 1101-1106.

Bull LT (1993) Nutrição mineral do milho. In: Bull LT, Cantarella H (Ed.). Cultura do milho: fatores que afetam a produtividade. Piracicaba: Potafos, p. 63-145.

Cantarella H \& Duarte AP (2004) Manejo de fertilidade do solo para a cultura do milho. In: Galvão, J. C. C.; Miranda, G. V. Tecnologia de produção de milho. Viçosa: UFV, p 139-182. 
Escosteguy PAV, Rizzardi MA \& Argenta G (1997) Doses e épocas de aplicação de nitrogênio em cobertura na cultura do milho em duas épocas de semeadura. Revista Brasileira de Ciência do Solo, 21: 71-77.

Fancelli AL \& Dourado Neto D (2004) Produção de milho. 2. ed. Guaiba, v. 1. 360 p.

Gava, GJC, Trivelin PCO, Oliveira MW, Heinrichs R \& Silva MA (2006) Balanço do nitrogênio da uréia (15N) no sistema soloplanta na implantação da semeadura direta na cultura do milho. Bragantia, 65: 477-486.

Lange A, Cabezas WARL \& Trivelin PCO (2008) Recuperação do nitrogênio das fontes sulfato e nitrato de amônio pelo milho em sistema semeadura direta. Pesquisa Agropecuária Brasileira, v. 43, p. 123-130.

Lara Cabezas WAR, Arruda MR, Cantarella H, Pauletti V, Trivelin PCO \& Bendassolli J. (2005) Imobilização de nitrogênio da uréia e do sulfato de amônio aplicado em pré-semeadura ou cobertura na cultura de milho, no sistema plantio direto. Revista Brasileira de Ciência do Solo, 29: 215-226.

Lara Cabezas WAR, Alves BJR, Caballero SSU \& Santana DG (2004) Influência da cultura antecessora e da adubação nitrogenada na produtividade de milho em sistema plantio direto e solo preparado. Ciência Rural, 34: 1005-1013.

Lara Cabezas WAR, Trivelin PCO, Kondorfer GH \& Pereira S (2000) Balanço da adubação nitrogenada sólida e fluida de cobertura na cultura de milho, em sistema plantio direto no Triângulo Mineiro (MG). Revista Brasileira de Ciência do Solo, 24: 363-376.

Malavolta E, Vitti GC \& Oliveira SA (1997). Avaliação do estado nutricional das plantas: princípios e aplicações. 2. ed. Piracicaba: Potafos, $319 \mathrm{p}$
Malavolta E, Pimentel-Gomes F \& Alcarde JC (2002). Adubos e adubação. São Paulo: Nobel, 200 p.

Martinez HEO, Carvalho JG \& Souza RB (1999) Diagnose foliar. Comissão de fertilidade do solo do estado de Minas Gerais CFSEMG. Recomendação para o uso de corretivos e fertilizantes em Minas Gerais: 5a aproximação, p.143-168.

Muzilli O (1983) Influência do sistema de plantio direto, comparado ao convencional sobre a fertilidade da camada arável do solo. Revista Brasileira de Ciência do Solo, 1: 95-102.

Pauletti V, \& Costa LC (2000) Épocas de aplicação de nitrogênio no milho cultivado em sucessão à aveia preta no sistema plantio direto. Ciência Rural, 30: 599-603.

Pottker D \& Wietholter S (2004) Épocas e métodos de aplicação de nitrogênio em milho cultivado no sistema plantio direto. Ciência Rural, 34: 1015-1020.

Sá JCM (1999) Manejo da fertilidade do solo no sistema plantio direto. In: Siqueira JO, Moreira FMS, Lopes AS, Guilherme LRG, Faquin V, Furtini Neto AE \& Carvalho JG (1999) (Ed.). Interrelação fertilidade, biologia do solo e nutrição do solo. Lavras: Ufla, Dcs, p.267-310.

Silva EC, Muraoka T, Buzetti S \& Trivelin PCO (2006) Manejo de nitrogênio no milho em Latossolo Vermelho sob plantio direto com diferentes plantas de cobertura. Pesquisa Agropecuária Brasileira, 41: 477-486.

Suhet AR, Peres JRR \& Vargas MAT (1986) Nitrogênio. In: Goedert WJ (Ed.). Solos dos cerrados: tecnologia e estratégias de manejo. Brasília: EMBRAPA, CPAC, 1986. p. 167-202. 